\title{
Urgences
}

\section{Où vont les voix, larghezze}

\section{Lucie Bourassa}

Numéro 27, mars 1990

Images imaginaires

URI : https://id.erudit.org/iderudit/025574ar

DOI : https://doi.org/10.7202/025574ar

Aller au sommaire du numéro

Éditeur(s)

Urgences

ISSN

0226-9554 (imprimé)

1927-3924 (numérique)

Découvrir la revue

Citer ce document

Bourassa, L. (1990). Où vont les voix, larghezze. Urgences, (27), 46-47.

https://doi.org/10.7202/025574ar

Ce document est protégé par la loi sur le droit d'auteur. L'utilisation des services d'Érudit (y compris la reproduction) est assujettie à sa politique d'utilisation que vous pouvez consulter en ligne.

https://apropos.erudit.org/fr/usagers/politique-dutilisation/
Cet article est diffusé et préservé par Érudit.

Érudit est un consortium interuniversitaire sans but lucratif composé de l'Université de Montréal, l'Université Laval et l'Université du Québec à Montréal. Il a pour mission la promotion et la valorisation de la recherche. https://www.erudit.org/fr/ 


\section{Où vont les voix, larghezze Lucie Bourassa}

Sostenuto, quatre nuits et un vent sombre dilacèrent la clarté de l'air. C'est une lente et lourde avancée que la pluie, si elle venait, ne parviendrait pas à freiner. Parce que cela un soir ou un matin a commencé et que cela pourrait toujours reprendre: venir redire le déroulement de tout. Quand l'apparente immobilité du visible, comme le centre d'un oil brûlé par l'éclipse, se creuse soudain du sonore, saigne alors le secret épuisement de ce qui va. (D'aucuns diraient qu'affleurent ces sources qu'on n'avait jamais perçues à travers l'opacité du sol...). Ici, dans cet étroit bougé, cinq voix essaient, par la poussée des timbres, de distendre le jour en épaisseur, de dilater ce peu même qu'est la seconde pour la saturer de matière. Mais rien, rien ne peut retenir le mouvement et nul ne sait où il se perd. Et tout au monde, malgré la dureté ou la sérénité simple de ses images, y sera emporté.

Alors, alors, va et laisse là, dans la rue, sur la neige ou dans ta maison quelques vieux os durcis, quelques pas acharnés, quelques gestes brisés et saute, saute de l'autre côté du voir, allonge tes bras, coule ton ventre et tes jambes, et surtout, pose un peu ta tête, couchée ou blessée, sur le dos des frottés et des soufflés, des nuits et du vent sombre qui t'attendent. Étends ta joue et ton oreille sur le fleuve de la clarinette. Ouvre la main droite, étire les doigts, prends une voix des cordes et enserre-la dans ta paume, connais le noir dans son tact. De l'autre main, effleure et oublie, tantôt l'aigu, tantôt le violoncelle - ou encore l'alto - et tiens, tiens longtemps cette main de l'autre qui avance et ouvrit pour toi l'insu du regard, qu'aucun faire n'atteint.

Quand, la première fois, je t'ai vu sommeiller dans ce larghetto, corps dépouillé puis enlacé par la lenteur, par le recueillement dans ses voiles morcelés, j’ai pensé qu'enfin le taire pouvait venir, et le sens avec lui. Je me suis tournée vers la fenêtre, j'ai regardé les quatre nuits et le vent évider, tresser les contours du temps dans le jour. Je t'ai vu pencher la tête, fermer les paupières et prendre le chant par la peau. $J$ 'ai vu les sons glisser dans tes cheveux et baigner ta nuque puis trembler tout près des reins. Ils tombent. Et poursuivent, encore, larghetto. Je suis allée te rejoindre. 
L'entrée dans ces tessitures allant un chemin s'est produite sans savoir ni heurt d'aucune sorte, sans cri ni ongle cassé - et la gorge avait oublié jusqu'à la sensation des serrements anciens. Les épaules d'abord et leur pli, soulevées d'un détachement subit, halées par les fluides sauts et ressauts des intervalles, quittèrent la tenue des actes et plongèrent dans la mince éraillure faite aux jours. Dans l'échancré de tout achèvement, antichambre des faits. Quelques rognures d'existence se sont alors dispersées sur les routes, les toits, les terrasses. À peine engagés dans le souffle de la clarinette, les coudes surpris apprirent le repos sous la chair à vif que déployait en son mouvoir la cantilène. Chair, et, à proprement dire, cœur de la vie, arrachée d'elle et la portant, voilà pourtant ce qu'elle n'est plus, ce dont elle s'abstrait nécessairement en son irruption même. Y être, c'était pourtant, plus que n'importe où ailleurs, toucher le vivre même en son affect, en sa motion qui épuise par-devers lui le visible. Ainsi, la clarinette emmenait doucement mes pieds très loin de chacun de leurs pas désormais oubliés. Et les quatre nuits tissaient une couche dont nous ignorions le lieu, l'heure et la destinée, dont nous ne pouvions rien dire, sauf qu'elle connaissait et traçait la portée du porter. Pour nous - et d'autres en même temps que nous, que la rencontre n'avait pas réunis dans le même ici, mais dont le là-bas, par la musique, ressemblait probablement au visage déplié du temps qui nous avait ici enserrés dans sa marche.

Et la dilatation en large, en long, et par devant, un devant qui monte ou descend, cette dilatation à quatre voix et une défaite de sanglot, dira peut-être, enfin (mais nul ne peut s'en assurer): que tout cela aille, avance, pour se perdre ou pour revenir. Que tout cela s'écoule - avec pour seule visée l'abandon même, l'emporté souterrain que chacun, sans savoir, a livré à l'insu, sous l'effarante évidence du monde. 